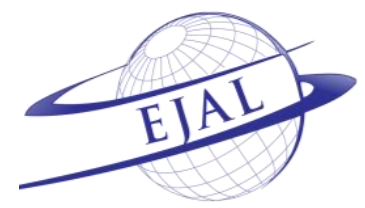

\title{
Corrective Feedback on Writing in EFL Context: Comparison of Two Approaches
}

\author{
Mine Gündüz Kartal a * (D), Derin Atay a † (D) \\ a Bahçeşehir University, Beşiktaş, İstanbul 34353, Turkey
}

\begin{abstract}
Received 26 September 2018 | Received in revised form 31 March 2019 | Accepted 25 May 2019
\end{abstract}
\begin{abstract}
APA Citation:
Gündüz Kartal, M. \& Atay, D. (2019). Corrective feedback on writing in EFL context: Comparison of two approaches. Eurasian Journal of Applied Linguistics, 5(3), 385-401. Doi: 10.32601/ejal.651390
\end{abstract}

\begin{abstract}
Although there is a disagreement among researchers on the effectiveness of corrective feedback (CF) in L2 writing (Ferris, 1999; Truscott, 1996; Truscott 1999), many studies proved that CF improves L2 learners' accuracy in writing over time. Therefore, instead of investigating the effectiveness of CF, some researchers carried out studies to investigate the effectiveness of different methods, techniques, approaches of applying CF (e.g. Bitchener, Young \& Cameron, 2005; Chandler, 2003; Tootkaboni \& Khatib, 2014) in L2 writing. Similarly, this current study was conducted to investigate the effects of two different corrective feedback types on L2 written performances. The first corrective feedback type is explicit feedback (cognitive-interactionist approach) in which the feedback is given directly, the other corrective feedback type is graduated feedback (sociocultural approach) in which the feedback is given as an assistance. The study conducted in one of the private universities in Turkey, with 11 Turkish EFL students. The students in the Explicit Feedback Group $(n=5)$, and the students in the Graduated Feedback Group $(n=6)$ completed their opinion paragraphs and received feedback according to the group they were assigned. After two weeks, the same procedure was applied to find out if there were any changes over time. The results of the study showed that the students in the Graduated Feedback Group were more successful in terms of doing self-correction than the students in the Explicit Feedback Group.

(C) 2019 EJAL \& the Authors. Published by Eurasian Journal of Applied Linguistics (EJAL). This is an open-access article distributed under the terms and conditions of the Creative Commons Attribution license (CC BY-NC-ND) (http://creativecommons.org/licenses/by-nc-nd/4.0/).
\end{abstract}

Keywords: Cognitive-interactionist approach; corrective feedback; explicit feedback; graduated feedback; sociocultural approach

\section{Introduction}

After the publication of Truscott's (1996) article, in which he shows clear opposition against grammar error correction in L2 writing (in this study, L2 writing and FL writing are used interchangeably), several scholars conducted studies to investigate whether error correction (corrective feedback) is helpful in L2 writing classes or not. Some of these studies' findings support that corrective feedback (hereafter CF) has no effect on the accuracy of L2 writing (e.g. Cohen \& Robins, 1976; Polio, Fleck \& Leder,

\footnotetext{
* Corresponding author. Tel.: +90-539-815-87-83

E-mail address: gunduzmine@gmail.com

$\dagger$ derin.atay@es.bau.edu.tr
} 
1998); on the other hand, some researchers found out that providing CF is evidently helpful in L2 writing (Ashwell, 2000; Ferris \& Roberts, 2001). Although the disagreement on the effectiveness of CF in L2 writing continues among researchers (Truscott, 1996; Ferris, 1999; Truscott 1999), many studies provided evidence that CF improves L2 learners' accuracy in writing over time. Therefore, instead of doing research on the effectiveness of $\mathrm{CF}$, some other researchers carried out studies to investigate the effectiveness of different methods, techniques, approaches of applying CF (e.g. Bitchener, Young \& Cameron, 2005; Chandler, 2003; Tootkaboni \& Khatib, 2014) in L2 writing.

Similarly, in this present study, the focus is on applying different types of CF approaches and their effects on L2 written performances. Before clarifying these approaches, it is worth explaining what $\mathrm{CF}$ means and how it is defined in the literature. As a general definition, $\mathrm{CF}$ is an interlocutor's responses to a learner's nontarget-like language production (Adams, Nueve, \& Egi, 2011). However, the issue of how to correct the non-target language production is not defined as simple as its definition by the researchers, that is why $\mathrm{CF}$ has been defined and investigated many times by different disciplines (e.g. psychology, linguistics) and by different approaches (Lyster \& Ranta, 1997). In this paper, two different approaches (cognitiveinteractionist approach and sociocultural approach) are taken into consideration to explain how to apply CF and what their effects are on L2 writing. The first approach in this study, which is cognitive-interactionist approach, characterizes CF as a set of clear strategies (e.g. recast, elicitation, explicit correction) which are implemented by an interlocutor to repair a learner's error(s) (Ortega, 2013). On the contrary, sociocultural approach accepts $\mathrm{CF}$ as a process in which a learner is supported to selfcorrect his/her non-target-like utterances (Aljaafreh \& Lantolf, 1994). The detailed definitions about $\mathrm{CF}$ stated by these two approaches and the studies conducted to investigate their effects on L2 writing (especially) are given below respectively.

\subsection{Corrective feedback in the cognitive-interactionist approach}

In cognitive-interactionist theory, corrective feedback is thought as a transfer of linguistic information from interlocutor to learner (Ortega, 2013). This transfer of linguistic information, in other words corrective feedback, generally ranges in its explicitness and implicitness. Implicit feedback does not intend to directly take the learner's attention to his/her incorrect utterance, whereas explicit feedback clearly indicates that the learner's production is not correct (Li, 2010). The most common strategy for implicit feedback, as Lystrer and Ranta (1997) state, is recasts which "involve the teacher's reformulation of all or part of a student's utterance, minus error" (p. 46). On the contrary, explicit correction both provides the correct form, and "overtly points out that what the student had said is incorrect" (p. 46).

Studies comparing implicit and explicit feedback strategies have not reached conclusive results. For example, in the study by Han (2002), recasts (implicit feedback) were found to be effective since they increased the awareness of the 
learners about using appropriate tenses during written performance. In another study by Mackey and Philp (1998), it is stated that although the effects of recasts may have been short-term, they were found to be beneficial for learners' interlanguage development. On the other hand, some studies (e.g. Ellis, Loewen, \& Erlam, 2006; Nagata, 1993) pointed out that explicit feedback is more effective than implicit feedback in terms of learner benefits and the learners who participated into these studies preferred explicit feedback. Nevertheless, explicit feedback (compared to the five other feedback techniques which are recast, elicitation, clarification request, metalinguistic feedback, repetition) was not found the most effective feedback technique in terms of learner's uptake in the study by Lyster and Ranta (1997). In a study of comparing explicitness and implicitness of the corrective feedback by Ferris and Roberts (2001), both types were found helpful and the learners could self-edit their mistakes. When these findings were considered, it is obvious that there is no consensus among the researchers on the effects of implicit and explicit feedback in the SLA literature.

\subsection{Corrective Feedback in the Sociocultural Approach}

In sociocultural theory (hereafter SCT), corrective feedback is not thought as a transfer of linguistic information from teacher to learner, rather it is defined as "a help that is jointly negotiated between experts and novices" (Aljaafreh \& Lantolf, 1994, p. 480). In other words, feedback is not seen as something in which erroneous part is pointed out to learners, rather it is seen as a process which is carried out by learner and teacher mutually. This view comes from Vygotsky's notion of Zone of Proximal Development (hereafter ZPD) which means "the distance between the actual developmental level as determined by independent problem solving and the level of potential development as determined through problem solving under adult guidance or in collaboration with more capable peers" (Vygotsky, 1978, p. 86). In another saying, ZPD assumes an interaction between a less competent person and a more competent person on a task, and the less competent person gradually becomes more independent on that task (Chaiklin, 2003). Therefore, in SCT, corrective feedback is supposed to be 'graduated' which means "the feedback adjusted to the level of the individual learner to enable them to self-correct" (Erlam et. al., 2013, p. 258).

In literature, there are not enough studies investigating the effectiveness of graduated feedback on written or oral performances. The most prominent and wellknown study, which focused on applying graduated feedback for error correction on written texts, was carried out by Aljaafreh and Lantolf (1994). In their study, the authors developed a regulatory scale, consisting of twelve regulations arranged from the most implicit to the most explicit, to identify the levels of the interactions between the expert (researcher) and the learners. As stated in the article, there are five transitional levels, and in the first three levels, learner depends heavily on the help of expert. However, in the level 4, learner finds the errors alone, but their performance in that level is not automatized. In the final level, learner's performance is automatized. In other words, learner uses the right forms of the linguistic information 
without any help, and very fast. After analyzing the audio-records between the researcher and the learners, they found that the learners needed less assistance to correct their mistakes and the feedback styles became more implicit and less explicit over time.

In the study by Ai (2017), the direction of the graduated feedback was just the opposite, in other words, the given feedback was from the most implicit to more explicit. In his study, different from many other CF studies, feedback was provided through a computer program called ICALL (intelligent computer-assisted language learning). The participants translated English sentences into Chinese language on that program and they had feedback when they made mistakes in their translations. The findings showed that having graduated feedback through this computer-assisted program was effective in enabling participants to self-identify and self-correct their erroneous parts in their translations.

In another study by Erlam et. al. (2013), which also inspired this current study, the cognitive-interactionist theory and sociocultural theory were compared to examine the effects of two different types of CF on L2 writing. One group of students had 'graduated feedback' (sociocultural theory) while the other group had explicit feedback (cognitive-interactionist theory). According to results, the group who had graduated feedback showed improvement in terms of self-correction but the there was no decrease in the amount of expert assistance over time. On the other hand, the group who had explicit feedback showed less improvement in terms of self-correction, but this type of feedback was implemented faster than the graduated feedback.

\subsection{Significance and Aim of the Study}

As stated earlier, there are not many studies examining the effects of different types of $\mathrm{CF}$ in accordance with different approaches on written or oral L2 performances. The most prominent and common studies which discuss the CF types (by taking sociocultural theory and cognitive-interactionist theory into consideration) on written L2 performances in literature are conducted by Aljaafreh and Lantolf (1994), Erlam et. al. (2013) and by Ai (2017). That is why, this study was set with the purpose of contributing to the literature by investigating the differences between the graduated feedback (sociocultural theory) and the corrective feedback (cognitiveinteractionist theory) on L2 writing in EFL context.

\subsection{Research Questions}

The present study aims to contribute to the literature by addressing the following research questions:

1. To what extent does (a) graduated feedback and (b) explicit feedback affect the learners' self-correction or uptakes during the feedback conferences? 
2. Is there any change in the students' responses when the (a) graduated feedback and (b) explicit feedback are provided successfully? If so, what are these changes?

\section{Method}

\subsection{Participants}

The participants of this study are Turkish EFL students who were studying in a preparatory school in one of the private universities in Turkey in the academic year of 2017-2018. At the time of the study, the participants were studying in the preintermediate (B1) level of English Language. In total, there were eleven (11) students who attended the study voluntarily, and these students were studying in the same class. Randomly, 6 of them were assigned to the Graduated Feedback Group, and 5 of them were assigned to the Explicit Feedback Group by the class instructor (researcher). There were 6 female and 5 male students whose ages range between 18 20 .

The other participants are the researchers of this study. One of the researchers is a $\mathrm{PhD}$ student and an EFL instructor for 10 years and she provided the graduated and the explicit feedback to the students' opinion paragraphs in one-to-one sessions. The other researcher is a professor in ELT department in one of the private universities in Turkey.

\subsection{Target structures}

Since the students wrote opinion paragraphs, they were expected to use variable structures (e.g. relative clauses, present tenses, gerunds and infinitives, articles, prepositions etc.). However, all these structures were not frequent enough in the students' opinion paragraphs except the two of them. That is why, the targeted structure was classified into two groups. The first group was present tense verb forms (e.g. simple present, use of auxiliary in present tense and in passive forms), and the second group was indefinite 'a/an' and definite 'the' articles with nouns.

\subsection{Procedure}

The participants of the study were given two topics to write an opinion paragraph, which is supposed to be around 200 words. They picked up one of the topics and wrote their opinion paragraphs in 60 minutes. After writing, the students had their feedback conferences individually according to the group they were assigned. In other words, the Graduated Feedback Group received 'graduated' correction while the Explicit Feedback Group received 'explicit' correction. Each feedback conference was audio-recorded in their entirety. 2 weeks later, the students were given another two topics to write an opinion paragraph. The allocated time and the expected length of opinion paragraph were the same as the first one. When the second writing finished, the researcher followed the same procedure. The feedback conferences were given to each student according to their groups, and all the conferences were audio-recorded 
again. In total, the students wrote two paragraphs and received two feedback conferences.

\subsection{Data collection instruments}

To answer the first research question, the data were gathered through the students' opinion paragraphs and the writing conferences held with the researcher. To answer the second research question, researcher kept field-notes during the conferences. Also, since all the conferences were audio-recorded, the researcher benefited from these recordings to evaluate the changes of the students' improvements in writing as well.

\subsection{Feedback conferences}

In the Graduated Feedback Group, the feedback conference started implicitly and according to students' needs (e.g. if a student could not find the error), the sentences were narrowed down to make the problematic part more obvious. However, during the conferences, the researcher did not point out any error directly. Instead, all the students were supported to self-correct their errors in their written texts.

In the Explicit Feedback Group, the feedback was given directly as the type of the feedback was explicit correction. The researcher took the attention of each student onto the erroneous part and provided correction explicitly.

\subsection{Coding the feedback conference data}

In both groups, all the conferences were audio-recorded and transcribed by the researcher. The researcher started each conference by focusing on the erroneous part. In the Graduated Feedback Group, the conferences were finalized either with a 'repair' (i.e. the learner produced the correct form (self-correction) or uptook the teacher's correction (uptake-with-repair)) or with 'no-repair' (i.e. the learner partially understood the teacher's feedback or failed to produce to correct linguistic form (no resolution)). In the Explicit Feedback Group, the conferences were finished by the students' either uptaking (uptake -with-repair) or not uptaking the correction (no resolution), but in some cases the learners in this group produced the correct forms on their own (self-correction) as well.

The regulatory scale for coding the feedback conferences was developed by Erlam et. al. (2013) and in this study, the researchers benefited from this scale. The scale has two sections. In the first section, there are variable strategies (i.e. read sentence/clause containing error, indicate there is something wrong with the sentence/clause, narrow down to smaller unit) for the teacher to provide the appropriate corrective feedback to the students. In the second section, there are categories for coding the repair or no-repair of a conference. 


\subsubsection{Example of graduated feedback conference}

In the example conference given below, the session starts by the teacher's reading the sentence containing an error, and between the lines 1-19, the teacher provides some strategies to make the student self-correct the mistake. Between the lines 20-24, the student self-corrects the mistake and resolution occurs.

A part of conference with Student 6 from the Graduated Feedback Group;

1.T: Ok. I want you to look at this sentence, 'the first reason is people who works..' (read the sentence containing error)

2. S: hmmm, hm.

3. T: can you see any problem in this sentence? (indicate sth is wrong with this sentence)

4. S: hmm, people is not... single... human.

5. T: yes, so?

6. S: ...and..... who works...

7. T: yes?

8. S: ....not correct.

9. T: yes. How can you correct this sentence?

10. S: Hmm..... I dont know.

11. T: This is (people) plural, true. (give a metalinguistic/grammar explanation)

12. S: yes.

13. T: with plural subjects, verb is singular or plural?

14. S: plural.

15. T: yes, so?

16. S: hhm, are?

17. T: No, ok. I am giving an example. People who.. go.. to university.... this is the correct one, compare it with your sentence. (give a metalinguistic/grammar example)

18. S: people who.... working?

19. T: No. (direct rejection of error)

20. S: hmmm, people..who.. work? (student self-corrects)

21. T: correct. (indicate student closing in on error)

22. S: (laughs).

23. T: yes, because only he/she/it subjects take -s with verbs, right? (give a metalinguistic/grammar explanation)

24. S: yes, yes. 


\subsubsection{Example of Explicit Feedback Conference}

In the example conference given below, the session starts as it is in the Graduated Feedback Group (the teacher read the error containing sentence); however, it continues and ends with the teacher's giving metalinguistic explanation.

A part of conference with Student 1 from the Explicit Feedback Group;

1.T: 'However, going to work is can be dull.' (read sentence containing error)

2.S:

3.T: There is a mistake, isn't it?

4.S: Hmmm, yes, yes.

5.T: 'can' and 'is' together? not possible, right? (give a metalinguistic/grammar explanation)

6.S: Hmmm?

7.T: In this sentence, we are not using 'is', because you used 'to be' verb already. 'can' ... good, and enough. (give a metalinguistic/grammar explanation)

\subsection{Data Analysis}

The first research question was answered by calculating the number of times each student was able to self-correct an error in consequence of working with the teacher or to uptake the teacher's feedback if self-correction did not occur. Besides, the number of episodes including no resolution was counted.

To answer the second research question, qualitative analysis strategies were used. The researcher's field notes and the recordings were used to evaluate whether there were any changes in the students' responses to the given feedback during the writing conferences over time.

\section{Results}

\subsection{Results for the RQ1}

In Table 1, there are the mean numbers of feedback episodes which took place in the Explicit Feedback Group and Graduated Feedback Group for 'present tense' and 'articles' in two writing conferences. Students in the Explicit Feedback Group had 6.20 mean number for the 'present tense' structure in the first writing conference; however, it was 5.80 in the second writing conference for the same structure (present tense). Also, their mean number decreased from 2.40 to 1.60 for the 'articles' structure. On the other hand, students in the Graduated Feedback Group showed similar performance from the first conference to second conference. Their mean number of feedback for the 'present tense' was 6.40 in the first writing conference, but it was 4.20 in the second conference. For the 'articles', while the mean number was 2.80 , it was 2.00 in the second conference. Both groups' feedback episodes showed a decrease from writing conference 1 to writing conference 2 . 
Table 1. The number of present tense and articles feedback

\begin{tabular}{|c|c|c|c|c|c|c|c|c|c|c|c|c|}
\hline \multirow[t]{3}{*}{ Group } & \multicolumn{6}{|c|}{ Present Tense } & \multicolumn{6}{|c|}{ Articles } \\
\hline & \multicolumn{2}{|c|}{ Conf.1 } & \multicolumn{2}{|c|}{ Conf. 2} & \multicolumn{2}{|l|}{ Total } & \multicolumn{2}{|c|}{ Conf.1 } & \multicolumn{2}{|c|}{ Conf. 2} & \multicolumn{2}{|c|}{ Total } \\
\hline & $M$ & $S D$ & $M$ & $S D$ & $M$ & $S D$ & $M$ & $S D$ & $M$ & $S D$ & $M$ & $S D$ \\
\hline $\begin{array}{l}\text { Exp. } \\
n=5\end{array}$ & 6.20 & 1.30 & 5.80 & 1.30 & 12.00 & 2.23 & 2.40 & 1.14 & 1.60 & 0.54 & 4.00 & 1.58 \\
\hline $\begin{array}{l}\text { Grad. } \\
n=6\end{array}$ & 6.40 & 2.30 & 4.20 & 0.83 & 10.60 & 2.40 & 2.80 & 0.83 & 2.00 & 0.70 & 4.80 & 1.92 \\
\hline
\end{tabular}

In Table 2, each learner's scores for self-correction, uptake-with-repair and no resolution are shown. In both Writing Conference 1 and Writing Conference 2, all the students (both Explicit Feedback Group and Graduated Feedback Group) received feedback on all errors, not only on present tense and articles (i.e. relative clauses, gerund and infinitives etc.). As it is seen in the table, self-correction occurred in both groups; however, the frequency of self-correction was higher in the Graduated Feedback Group when it was compared to the Explicit Feedback Group. Also, the number of uptake-with-repair was lower in the Graduated Feedback Group since each student in this group was expected to correct his/her mistakes on his/her own. In the Explicit Feedback Group, the students had higher number of uptake-with-repair in both writing conferences. Therefore, it can be said that the students' responses to the feedback types were different in each group.

Table 2. Each learner's scores for self-correction, direct correction and no resolution in writing conference 1 and 2

\begin{tabular}{|c|c|c|c|c|c|c|}
\hline Student Writing con & ace 1 & & Writing col & rence 2 & & \\
\hline Self-correction & Uptake-with-repair & No resolution & $\begin{array}{l}\text { Self- } \\
\text { correction }\end{array}$ & $\begin{array}{l}\text { Uptake-with- } \\
\text { repair }\end{array}$ & $\begin{array}{l}\text { No } \\
\text { resolution }\end{array}$ & \\
\hline Explicit feedback stu & & & & & & \\
\hline S.1 & 4 & 7 & 0 & 5 & 7 & 0 \\
\hline S.2 & 5 & 7 & 0 & 3 & 5 & 0 \\
\hline S.3 & 9 & 19 & 2 & 4 & 8 & 3 \\
\hline S.4 & 5 & 12 & 3 & 6 & 10 & 0 \\
\hline S.5 & 1 & 13 & 1 & 2 & 5 & 0 \\
\hline Graduated feedback & nts & & & & & \\
\hline S.1 & 12 & 1 & 1 & 7 & 1 & 0 \\
\hline S.2 & 21 & 1 & 3 & 19 & 2 & 0 \\
\hline S.3 & 6 & 0 & 1 & 9 & 0 & 0 \\
\hline S.4 & 12 & 0 & 1 & 14 & 1 & 0 \\
\hline S.5 & 6 & 0 & 1 & 9 & 0 & 0 \\
\hline S. 6 & 5 & 0 & 2 & 12 & 3 & 1 \\
\hline
\end{tabular}




\subsection{Results for the RQ2}

To determine whether there were any changes in the students' responses to the given feedback during the writing conferences, the recordings of students in each group and the researcher's field notes were used. Also, the total time spent for both groups in two conferences was calculated to examine if there were any decrease or increase related to the spent time in the conferences. Table 3 shows the mean number of allocated time (minutes) in each group and in each conference. In total, the researcher spent an average of $11 \mathrm{~min} 48 \mathrm{~s}$ for each student in the Explicit Feedback Group, whereas the researcher spent an average of $19 \mathrm{~min} 64 \mathrm{~s}$ in the Graduated Feedback Group for each student.

Table 3. Spent time in each group and conference

\begin{tabular}{|c|c|c|c|c|c|c|}
\hline \multirow[t]{3}{*}{ Group } & & & & & & \\
\hline & \multicolumn{2}{|l|}{ Conf.1 } & \multicolumn{2}{|c|}{ Conf. 2} & \multicolumn{2}{|l|}{ Total } \\
\hline & $M$ & $S D$ & $M$ & $S D$ & $M$ & $S D$ \\
\hline $\begin{array}{l}\text { Exp. } \\
n=5\end{array}$ & 7.31 & 2.32 & 4.16 & 1.02 & 11.48 & 3.17 \\
\hline $\begin{array}{l}\text { Grad. } \\
n=6\end{array}$ & 11.97 & 6.07 & 7.67 & 2.17 & 19.64 & 7.00 \\
\hline
\end{tabular}

To evaluate the changes of the students' responses to the given feedback over time, the transcripts of two students' (one from the Explicit Feedback Group, one from the Graduated Feedback Group) writing conference 1 and 2 are given below. Since the students received feedback for all the mistakes in both conferences, only some part of the transcripts including present tense and articles feedback were taken and illustrated below. Besides, the researcher's field notes are added after each student's conference 1 and 2 .

Conference 1 with Student 4 from the Explicit Feedback Group

1.T: Ok. Let's start. 'for example, people don't need to use transportation'. This sentence is ok.

Let's continue.

2.S: Ok.

3.T: 'It is look like a cheap'. No. We don't use 'is' in this sentence. We remove 'is' and, we add '-s' to the verb, so... it looks like a cheap.*

4.S: Ok.

5.T: but, 'a cheap' what?

6.S: hmmm, cheap... prize?

7.T: hmmm, what about... cheap... option? *

8.S: Ok. 
This conversation, with student 4 , was held between the first 34 seconds and the first minute, and in total this conference lasted $8 \mathrm{~min} 28 \mathrm{~s}$. Table 4 given below describes the techniques used with the student during this part of conference.

Table 4 . The techniques used with student 4 in conference 1

\begin{tabular}{llr}
\hline Line & Technique Name & Technique Number \\
\hline 3 & Giving metalinguistic description of error & 5 \\
3 & Giving metalinguistic/grammar explanation & 6 \\
3 & Supplying correct form & 7 \\
7 & Supplying correct form & 7 \\
\hline
\end{tabular}

\section{Conference 2 with Student 4 from the Explicit Feedback Group}

1.T: Let's begin.

2.S: Ok.

3.T: 'Studying with friends is great option for the following reasons'. Ok. Hmmm, 'great' is adjective here, right? and... 'option' is..noun, so... in this sentence, you need something... article?*

4.S4: hmmm, yes.

5.T: So, it should be 'studying with friends is... a... great option?*

6.S4: Ah, yes.

7.T: Good. Let's continue. 'First of all, people most of the time likes to...' hmmm, people is a plural noun, right?*

8.S4: Yes.

9.T: So, not likes... it is...?

10.S4:

11.T: like?*

12.S4: Yes.

This conversation, with the same student, was held in the first 20 seconds of the conference, and in total this conference lasted 5 min $58 \mathrm{~s}$. Table 5 given below describes the techniques used with the student during this part of conference.

Table 5. The techniques used with student 4 in conference 2

\begin{tabular}{llr}
\hline Line & Technique & Technique Number \\
\hline 3 & Giving metalinguistic/grammar explanation & 6 \\
5 & Supplying correct form & 7 \\
7 & Giving metalinguistic/grammar explanation & 6 \\
11 & Supplying correct form & 7 \\
\hline
\end{tabular}




\section{Researcher Field Notes}

Student 4 in the Explicit Feedback Group had 12 explicit correction in conference 1, and 10 explicit correction in conference 2 (see Table 2 ). In both conferences, when the self-corrections were put aside, the same techniques were used to correct the student's mistakes and these techniques were: giving metalinguistic description of error (technique 5), giving metalinguistic/grammar explanation (technique 6), and supplying correct form (technique 7) (see Appendix A, Section 1).

\section{Conference 1 with Student 3 from the Graduated Feedback Group}

1.T: 'If any connection problem occur while...' Ok. In this sentence, we have a problem. Can you see it?*

2.S: any? Is this problem?

3.T: No, it is ok, you can use 'any' in this sentence.

4.S: Hmmm, I can't find it.

5.T: Can you look at the subject and the verb?*

6.S: Subject and the verb?

7.T: Yes. What is the subject of your sentence?

8.S: Subject is... hmmm, connection problem?

9.T: True, so your verb is..

10.S: Verb?

11.T: Yes, what is your verb?

12.S: Occur?

13.T: Yes, connection problem... occur...? ok. Connection problem refers to what? He, she, it, you, we, they?

14.S4: It.

15.T: Ok, connection problem refers to 'it'. When we use 'it' as a subject, what happens to the verb in simple present tense?

16.S4: Connection problem is occur?

17.T: No.*

18.S4:

19.T: For example, it rains, it stops...*

20.S4: occurs? *

21.T: Correct. Thank you.

This conversation, with student 3 , was held between 3.49 and 5.17 , and in total this conference lasted $10 \mathrm{~min} 2 \mathrm{~s}$. Table 6 given below describes the techniques used with the student during this part of conference. 
Table 6. The techniques used with student 3 in conference 1

\begin{tabular}{llr}
\hline Line & Technique & Technique Number \\
\hline 1 & Reading sentence containing error & 1 \\
1 & Indicating there is something wrong & 2 \\
5 & Narrowing down & 3 \\
$6-15$ & Giving metalinguistic/grammar explanation & 6 \\
17 & Direct rejection of error & $8(\mathrm{a})$ \\
19 & Giving metalinguistic/grammar explanation & 6 \\
\hline
\end{tabular}

\section{Conference 2 with Student 3 from the Graduated Feedback Group}

1.T: Ok, let's read your paper. 'Although some people believe that there is not much options for the summer holiday..."*

2.S: Many, I think. Not 'much'.

3.T: Very good, so quick.

4.S: After I read, I saw it.

5.T: ok. 'there isn't many options..' but, there is still one more problem here.*

6.S:

7.T: Look at the tense.*

8.S: There is.. hmmm, don't have?

9.T: No, no. many options...plural right?**

10.S: Yes.

11.T: the beginning of the sentence...

12.S: ooh, there are..are.*

13.T: Yes. Thank you.

This conversation, with the same student, was held in the first 45 seconds of the conference, and in total this conference lasted $7 \mathrm{~min} 48 \mathrm{~s}$. Table 7 given below describes the techniques used with the student during this part of conference.

Table 7. The techniques used with student 3 in conference 2

\begin{tabular}{llr}
\hline Line & Technique & Technique Number \\
\hline 1 & Reading sentence containing error & 1 \\
5 & Indicating there is something wrong & 2 \\
7 & Narrowing down & 3 \\
9 & Direct rejection of error & $8(\mathrm{a})$ \\
9 & Giving metalinguistic/grammar explanation & 6 \\
\hline
\end{tabular}




\section{Researcher Field Notes}

Student 3 in the Graduated Feedback Group self-corrected his mistakes 6 times in conference 1, and 9 times in conference 2 (see Table 2). The techniques 1, 2, 3, 6, 8(a) were the most frequent ones. Both conversations ended with the student's selfcorrection, also the conference 2 started with the student's self-correction.

\section{Discussion}

The present study was conducted with the purpose of investigating two different CF types based on two different approaches. The first CF type was 'explicit feedback' which is defined in cognitive-interactionist approach as giving feedback to a learner directly. The second CF type used in this study was 'graduated feedback' coming from sociocultural approach and it basically means a process in which a learner is assisted to find the mistakes on his own, or with the support of a teacher. Results of the two research questions are discussed respectively.

The first research question of this study is; 'to what extent does (a) graduated feedback and (b) explicit feedback affect the learners' self-correction of their errors or uptaking the teacher's corrective feedback in the feedback conferences?'. When Table 2 is analyzed, it is seen that the total number of the self-correction in the Graduated Feedback Group is 132 out of 151 mistakes, while it is 44 out of 145 in the Explicit Feedback Group. From this result, it can be said that the students in the Graduated Feedback Group found \%87 of their mistakes on their own, which means graduated feedback type enabled the students to correct their mistakes more successfully than the explicit feedback type. This high rate of correction result shows a similarity with the study by Frantzen and Rissell (1987) in which the learners could correct \%93 of their errors in 10-min in-class feedback conferences. On the other hand, the students in the Explicit Feedback Group found \%30 of their mistakes by self-correction. Compared to the Graduated Feedback Group, this rate is lower; however, this number is quite high when it is compared to the study by Erlam et. al. (2013) in which the total rate of self-correction was \%3.3 in the Explicit Feedback Group.

This high rate, in both groups, might be also explained by the students' level of English which was pre-intermediate at the time of the study, and another possible reason might be the students' awareness about the corrective feedback. Normally, as school procedure requires, the students write their opinion paragraphs in the lesson time, the teachers code the erroneous parts (i.e. writes ' $T$ ' for 'tense errors') and then they distribute these coded papers to students to correct their mistakes and write another draft. Although the students were given feedback individually through conferences for that study, it was not the first time for them to have feedback for their written performances. Therefore, their awareness of correcting their mistakes on their written performances might have been higher than usual, and this awareness may have affected their correction performances.

When it comes to the uptakes (i.e. responses to feedback), which is the second part of the first research question, it was done ten times more in the Explicit Feedback 
Group (92) than the Graduated Feedback Group (9). As it is stated before, the students in the Graduated feedback group were expected to correct their mistakes on their own; therefore, this difference between the groups was possible. This result shows parallelism with the results of the study by Erlam et. al. (2013). In that study, uptakes in the Graduated feedback group was lower than the Explicit feedback group. However, all the uptakes were not resolved by the students in both groups, especially by the Graduated Feedback Group in the first writing conference. This result may support the claim by Ellis, Loewen, \& Erlam, (2006) and Nagata (1993) who found explicit feedback more effective and beneficial for learners. Also, in the study by Ferris, Chaney, Komura, Roberts, and McKee (2000), it was stated that the learners who had explicit feedback had higher rate of correct revisions (88\%) than the learners who had implicit feedback (77\%). Though, clearly, explicit feedback is not as effective as graduated feedback in enabling the learners to self-correct their mistakes, it helps them to resolve their mistakes on their writing performances better.

The second research question in this study is; 'is there any change in the students' responses when the (a) graduated feedback and (b) explicit feedback are provided successfully? If so, what are these changes?'. When Table 4 and Table 5 were compared for the explicit feedback, it was seen that in both conferences the same feedback techniques were used, and when the responses of the S4 (student four) were compared, there was also no change over time. When the Table 6 and Table 7 were compared for the graduated feedback, it was also found that the same techniques were needed in both conferences. However, when the student's (S3) responses were checked, it was seen that the conference 2 started with the student's self-correction, which might be accepted as a change or an improvement in the successful implementation of graduated feedback. This finding shows a similarity with the study by Erlam et. al. (2013) in which the number of strategies were counted to see the possible changes. However, as in this study, there was no apparent changes in both graduated feedback group and explicit feedback group. To see the changes, the time of the study may have been longer, which is one of the limitations of this current study. Also, as stated by Ferris (2004), in many L2 writing error feedback studies, the delayed effects of the given feedback are missing, which might be another limitation. Further research on feedback in L2 writing may be conducted by taking these limitations into account.

\section{Conclusion}

The results of this study showed that Graduated Feedback Group, in which the learners were assisted to find their mistakes, were more successful in self-correction than the Explicit Feedback Group. In other words, graduated feedback which comes from sociocultural approach enabled L2 learners to find their own mistakes in their writing performances more effectively than the explicit feedback coming from cognitive-interactionist approach. Hence, it might be possible to say that providing graduated feedback can be helpful for the teachers aiming to assist their learners in L2 writing classes rather than showing the erroneous parts directly. 
On the other hand, the time spent on delivering feedback for these two different feedback types needs to be evaluated. When the results of total time spent for each group is analyzed, it is obvious that giving graduated feedback takes much more time than the explicit feedback. Therefore, it can be said that applying explicit feedback is more effective for the teachers of large classes as it is conducted in a shorter time and a quicker way.

This study did not aim to show the better type of CF, it aimed to compare two different CF types coming from different approaches. When all the study is taken into consideration and compared to the similar studies (Ai, 2017; Aljaafreh \& Lantolf, 1994; Erlam et. al., 2013), it can be concluded that both CF types are effective in terms of different aspects. In education, if the purpose is enabling learners to selfcorrect their mistakes, but with help of a teacher, obviously sociocultural approach based on Vygotskian notion is preferable. However, if the purpose is to provide the correct information from an expert to novice in a shorter time and a quicker way, the cognitive-interactionist approach is more effective.

\section{References}

Adams, R., Nueve, A., \& Egi, T. (2011). Explicit and implicit feedback, modified output, and SLA: Does explicit and implicit feedback promote learning and learner-learner interactions? The Modern Language Journal, 95 (1), 42-63. https://doi.org/10.1111/j.15404781.2011.01242.x

Ai, H. (2017). Providing graduated corrective feedback in an intelligent computer-assisted language learning environment. ReCall, 29(3), 313-334. https://doi.org /10.1017/ S095834 401700012X

Aljaafreh, A. L., \& Lantolf, J. P. (1994). Negative feedback as regulation and second language learning in the zone of proximal development. The Modern Language Journal, 78(4), 465483. https://doi.org /465-483. 10.2307/328585

Ashwell, T. (2000). Patterns of teacher response to student writing in a multiple-draft composition classroom: Is content feedback followed by form feedback the best method? Journal of Second Language Writing, 9, 227-258. https://doi.org/10.1016/S10603743(00)00027-8

Bitchener, J., Young, S., \& Cameron, D. (2005). The effect of different types of corrective feedback on ESL student writing. Journal of Second Language Writing, 14(3), 191-205. https://doi.org/10.1016/j.jslw.2005.08.001

Cohen, A. D., \& Robbins, M. (1976). Toward assessing interlanguage performance: The relationship between selected errors, learners' characteristics, and learners' expectations. Language Learning, 26, 45-66. https://doi.org/10.1111/j.1467-1770.1976.tb00259.x

Chaiklin, S. (2003). The zone of proximal development in Vygotsky's analysis of learning and instruction: Vygotsky's Educational Theory in Cultural Context, New York: Cambridge University Press.

Chandler, J. (2003). The efficacy of various kinds of error feedback for improvement in the accuracy and fluency of L2 student writing. Journal of Second Language Writing,12, 26796. https://doi.org/10.1016/S1060-3743(03)00038-9 
Ellis, R., Loewen, S., \& Erlam, R. (2006). Implicit and explicit corrective feedback and the acquisition of L2 grammar. Studies in Second Language Acquisition, 28(2), 339-368. https://doi.org/10.1017/S0272263106060141

Erlam, R., Ellis, R., \& Batstone, R. (2013). Oral corrective feedback on L2 writing: Two approaches compared. System, 41(2), 257-268. https://doi.org/10.1016/j.system.2013. 03.004

Ferris, D. (1999). The case for grammar correction in L2 writing classes: A response to Truscott (1996). Journal of Second Language Writing, 8(1), 1-11. https://doi.org/10.1016/ S1060-3743(99)80110-6

Ferris, D. R. (2004). The "grammar correction" debate in L2 writing: Where are we, and where do we go from here?(and what do we do in the meantime...?). Journal of Second Language Writing, 13(1), 49-62. https://doi.org/10.1016/j.jslw.2004.04.005

Ferris, D. R., Chaney, S. J., Komura, K., Roberts, B. J. \& McKee, S. (2000). Perspectives, problems, and practices in treating written error. In Colloquium presented at International TESOL Convention, Vancouver, B.C., March 14-18.

Ferris, D., \& Roberts, B. (2001). Error feedback in L2 writing classes: How explicit does it need to be? Journal of Second Language Writing, 10, 161-184. https://doi.org/10.1016/S10603743 (01)00039-X

Frantzen, D., \& Rissell, D. (1987). Learner self-correction of written compositions: What does it show us? Foreign Language Learning: A Research Perspective, Cambridge University Press.

Han, Z. (2002). A study of the impact of recasts on tense consistency in L2 output. TESOL Quarterly, 36(4), 543-572. https://doi.org/10.2307/3588240

Li, S. (2010). The effectiveness of corrective feedback in SLA: A meta-analysis. Language Learning, 60(2), 309-365. https://doi.org/10.1111/j.1467-9922.2010.00561.x

Lyster, R., \& Ranta, L. (1997). Corrective feedback and learner uptake. Studies in Second Language Acquisition, 19(1), 37-66. https://doi.org/10.1017/S0272263197001034

Mackey, A., \& Philp, J. (1998). Conversational interaction and second language development: Recasts, responses, and red herrings? The Modern Language Journal, 82(3), 338-356. https://doi.org/10.1111/j.1540-4781.1998.tb01211.x

Nagata, N. (1993). Intelligent computer feedback for second language instruction. The Modern Language Journal, 77(3), 330-339. https://doi.org/10.1111/j.1540-4781.1993.tb01980.x

Ortega, L. (2013). Understanding second language acquisition. New York, NY: Routledge.

Tootkaboni, A. A., \& Khatib, M. (2014). The efficacy of various kinds of error feedback for improvement in the writing accuracy of Iranian EFL learners. Bellaterra Journal of Teaching \& Learning Language \& Literature, 7(3), 30-46. https://doi.org/10.5565 $/$ rev/jt13.529

Truscott, J. (1996). The case against grammar correction in L2 writing classes. Language Learning, 46, 327-369. https://doi.org/10.1111/j.1467-1770.1996.tb01238.x

Truscott, J. (1999). The case for "The case against grammar correction in L2 writing classes": A response to Ferris. Journal of Second Language Writing, 8(2), 111-122. https://doi.org/10.1016/S1060-3743(99)80124-6

Vygotsky, L. S. (1978) Mind in society. Cambridge, MA: Harvard University Press.

\section{Copyrights}

Copyright for this article is retained by the author(s), with first publication rights granted to the Journal.

This is an open-access article distributed under the terms and conditions of the Creative Commons Attribution license (CC BY-NC-ND) (http://creativecommons.org/licenses/by-nc-nd/4.0/). 